\title{
Crónica del primer encuentro de Bioética y Derecho Animal - Quito, 18 de mayo de 2018
}

\author{
Verónica Aillón Albán \\ Coordinadora, Fundación Victoria Animal, Quito-Ecuador \\ Master Derecho Animal (UAB) \\ ORCID: 0000000152148910
}

Recepción: Mayo 2018

Aceptación: Junio 2018

\section{Resumen}

La presente crónica recoge el desarrollo del Primer Encuentro de Bioética y Derecho Animal que tuvo lugar en la ciudad de Quito el 18 de mayo de 2018. Constituye una memoria de las ponencias presentadas así como el resultado de las mesas de trabajo: la Declaración de Quito, carta de intención suscrita por los participantes y que ha sido entregada al Grupo Parlamentario por el Bienestar Animal.

Palabras clave: Bioética, derecho animal, dignidad, reformas, debate, legislación.

Abstract. Chronicle of the First Meeting of Bioethics and Animal Law- Quito, 18th May 2018

This chronicle looks forward to save the memory of the First Meeting of Bioethics and Animal Law, Quito, May 18, 2018. It is a report of the papers presented as well as the result of the working groups: the Declaration of Quito, document already delivered to the Parliamentary Group for Animal Welfare of the National Assembly

Keywords: Bioethics, Animal Law, dignity, reforms, debate, legislation. 
El 18 de mayo de 2018, en la ciudad de Quito, Ecuador, se llevó a cabo el Primer Encuentro de Bioética y Derecho Animal centrado en las apreciaciones filosóficas, políticas, éticas y jurídicas de la relación con los animales.

La fundación Victoria Animal integrado por Pamela Bassante, Lorena Bellolio, Tatiana Calderón, Silvia Di Santo, Lucía Salazar, Carlos Vásconez y Verónica Aillón, organizó el evento con el auspicio de la Universidad San Francisco de Quito, la Sociedad de Estudiantes de Jurisprudencia SEJUR, el Colegio de Abogados de Pichincha, la Viceprefectura de Pichincha, Dulce Albahaca, la Secretaría de Salud del Distrito Metropolitano de Quito y Vicky Araujo Diseño.

El evento se desarrolló en el salón azul de la Universidad San Francisco de Quito y dio inicio con el registro de los participantes.

El primer punto del orden del día, que daría color a todo el evento fueron las notas del Himno a la Alegría de Beethoven.

La ilustre presencia de la Dra. Marita Giménez Candela, Coordinadora del Master en Derecho Animal en la Universidad Autónoma de Barcelona y la presencia virtual de la filósofa francesa Corinne Pelluchon, autora del libro: Manifiesto Animalista dieron realce a este evento.

La bienvenida estuvo a cargo de la Coordinadora de la fundación Victoria Animal, Dra. Verónica Aillón, quien compartió el motivo del nombre de la fundación, "lograr que los animales consigan victoria en su relación con los humanos, que se rescate su dignidad y el respeto hacia ellos”.

Posteriormente tomó la palabra el Dr. Farith Simon, decano de la Facultad de Jurisprudencia de la Universidad San Francisco, quien manifestó la apertura de la Universidad para tratar el estatus de la naturaleza y animales como sujetos de derechos y resaltó el hecho de que en esta misma ciudad de Quito, por los años 1800 Humboldt revolucionara el mundo científico al percibir la naturaleza como una red viva interconectada, al igual que este encuentro, que dará lugar a debates en la esfera jurídica al enfocar este tema.

La primera ponencia estuvo a cargo de la Dra. Marita Gimenez, que citó la historia de los esclavos y su camino hacia la liberación a través de visibilizar su categorización, realizó una exposición técnica sobre la propiedad, enfatizando que aquella no está vinculada necesariamente al maltrato, pasando por la cita de que los animales "no son algo, son alguien”compartiendo el trabajo que en España se realiza por parte de académicos especializados en diferentes sectores, como el de los colegios de abogados, el ICALP (International Center for Animal Law and Policies), la revista jurídica dA: Derecho Animal (Forum of Animal Law Studies) y el Master en Derecho Animal, esfuerzos jurídico académicos encaminados a profundizar en el estudio del estatus jurídico de los animales y sus distintas aristas y la inclusión o reforma de la normativa vigente hacia nuevos regímenes que se adecúen a la consideración e inclusión de los animales como seres vivos dotados de sensibilidad y dignidad.

Señaló los dos grandes pilares de la protección de los animales, el derecho de propiedad y la protección del maltrato y enfatizó en la necesidad de conjugar la ciencia con el derecho e incluir la sintiencia animal como punto de partida.

Con los antecedentes jurídicos a lo largo del tiempo y los diferentes países, terminó su intervención citando la "tenencia responsable” como la respuesta, que es la aplicación de la realidad de que son seres sintientes, capaces de sufrir, en los estatutos jurídicos.

La segunda intervención estuvo a cargo de la profesora Corinne Pelluchon, quien a través de videoconferencia compartió la lectura de su trabajo: "Los animales o la prueba de nuestra justicia”. Citó la ética animal como las dos primeras olas de la filosofía de la animalidad, la ética animal en las décadas de 1970 y 1980 ( Singer y Regan), el humanismo impugnado por la animalidad (Derrida), animalismo y humanismo.

Mantiene que la causa de los animales es también la causa de la humanidad y que debe ser un tema politizado.

Por lo que invitaba a pensar una zoopolítica que contenga estrategias políticas y 
perspectivas futuras a corto plazo y largo plazo, radicalidad y pragmatismo, y la educación y ética de las virtudes.

Luego de las inspiradoras palabras de las conferencistas invitadas, se conformó el primer panel del evento, que dio inicio con la ponencia de la Dra. Verónica Aillón que trató sobre la normativa vigente en el Ecuador y la necesidad de que se tome en cuenta la sintiencia animal en todas las normas jurídicas, más allá de las necesidades humanas o las justificaciones de salud u otras basadas en el antropocentrismo, sino en el reconocimiento del derecho a existir libremente de todos los seres que habitamos el planeta sin que una especie tiranice a las demás. Citó a la filósofa Marta Nussmabaum y el derecho de todos los seres al florecimiento, que actualmente no puede ser desarrollado por los animales por la conveniencia de la especie humana.

Continuando con el panel tomó la palabra el Dr. Luis Ávila, delegado de la Defensoría Pública, quien reflexionó sobre la normalización social del hecho de matar para comer desarrollado por la humanidad, señalando que aquello es una macabra ideología de la animalidad, basada en las siguientes ideas: Los animales: a) No son racionales, b) No aman y c) Son cosas.

Para que ocurra la aceptación de estas ideas, el humano debe ser el centro, sin embargo es urgente que se supere el especismo, citó a Eugenio Zaffaroni quien sostiene que las capacidades de los animales en algunos casos son superiores a las humanas, algunos ven en la noche, otros perciben olores a 4 kilómetros, otros pueden cargar 20 veces su peso, entonces, su capacidad de racionalidad es distinta a la humana, lo que no quiere decir que no exista.

El tercer panelista fue el Dr. Hugo Echeverría, quien se refirió al derecho penal, fortalezas y debilidades de la normativa vigente y análisis para las posibles reformas.

Comentó que anteriormente en caso de maltrato animal, no se tomaba en cuenta el perjuicio al animal en sí, sino a el daño que se le causaba al dueño, a la seguridad pública o a la posible afectación a un humano. En el Código Integral Penal actual (2014) incluye a los animales de compañía como el bien jurídico protegido, regula las lesiones causadas por maltrato y la muerte, no contempla ni el abandono ni la zoofilia, lo que la hace insuficiente, tanto por su contenido como por su calidad de contravenciones, la pena aplicable es 50 a 100 horas de servicio comunitario, en caso de muerte de tres a siete días, en caso de combate de 15 a 30 días, lo que cuestiona la proporcionalidad de la pena frente a la gravedad de los hechos y evidencia la necesidad de reformar el texto, fortalecer las sanciones y armonizarlas con las de países vecinos (1 a 3 años).

Terminó diciendo a la audiencia, que en la Asamblea Nacional se están estudiando dos proyectos de ley de reforma al COIP e invitando al debate legislativo que está abierto a quienes deseen participar.

Luego de este panel se instaló el segundo, que dio inicio con la ponencia del Dr. José Ruales, Secretario de Salud del Distrito Metropolitano de Quito, que se refirió a la interacción entre salud pública y fauna urbana, indicando que el problema que persiste

son las mordeduras.

Recordó que en el año 2011 se incluye el tema de bienestar animal en las ordenanzas seccionales y por primera vez se incluyen sanciones por maltrato y muerte.

En estas ordenanzas también se restringe la venta de animales de compañía en lugares públicos y el control de criaderos. Sin embargo, insiste el Dr. Ruales, los animales son considerados cosas, propiedad de sus dueños, no se los define como seres vivos que tienen derechos.

Afortunadamente, continuó el panelista, en diciembre del año pasado se emite por parte del Distrito Metropolitano de Quito la Ordenanza 188 incluye a los animales como parte de los grupos vulnerables y se le da la potestad de vigilar ese derecho a la Secretaría de Inclusión Social del Municipio.

Para controlar la sobrepoblación, indicó las campañas de esterilización que se realizan periódicamente así como las ferias y talleres de sensibilización y bienestar animal 
que se realizan desde esta Secretaría.

A continuación se presentó la ponencia del Dr. Sebastián Palacios, integrante del Grupo Parlamentario por el Bienestar Animal, integrado por 11 asambleístas de diferentes provincias y tendencias políticas.

Mencionó la necesidad de una reforma al estatus jurídico de los animales en el régimen jurídico, principalmente en el Código Civil.

Así también comentó el proyecto de reformas al COIP sobre el tema trabajado por este Grupo Parlamentario, indicando que actualmente la sanción para maltrato es de 20 a 50 horas de trabajo comunitario y de 3 a 7 días para lesiones y muerte; la propuesta es de incluir nuevos artículos que sancionen la zoofilia, el bestialismo y el abandono. Y fortalecer las sanciones con la pena de prisión por el lapso de 6 meses a 1 año si se trata de maltrato, y si hay muerte del animal con prisión de 1 a 3 años.

El delito de abandono será sancionado con 30 días de privación de la libertad.

La experimentación con pena de 6 meses a 1 año de prisión.

La introducción de nuevas especies que afecten el equilibrio ecológico será sanciando con la pena de uno a tres años de prisión.

Hizo un parangón entre la violencia hacia los animales con la violencia entre humanos, indicando que la posibilidad de atacar a vecinos, hijos, hermanos, parejas, asciende si el agresor atacó a un animal.

Terminó su intervención invitando a los participantes a presentar sus propuestas de reformas legales para hacer un trabajo coordinado y seguir creciendo como sociedad.

Posteriormente tuvieron lugar 7 mesas de trabajo. Cada una de las mesas debatió sobre un tema, dando lugar a la Declaración de Quito, que recoge las conclusiones resultado del debate.

En próximos días se firmará el convenio entre la Defensoría Pública, Victoria Animal, PAE, LIBERA Ecuador y el ICALP para incluir el tema de defensa y promoción de derechos de los animales como víctimas comenzando por Quito para luego extenderse a todo el territorio ecuatoriano.

\section{ANEXO \\ DECLARACIÓN DE QUITO. PRIMER ENCUENTRO DE BIOÉTICA Y DERECHO ANIMAL}

Quito, 18 de Mayo de 2018

Los participantes en las Mesas de Trabajo constituidas en el marco del Primer Encuentro de Bioética y Derecho Animal realizado en la ciudad de Quito, en la Universidad San Francisco de Quito el 18 de Mayo de 2018, como resultado de los debates sobre las cuestiones morales y éticas discutidas durante el evento, aprueban el siguiente documento:

Las premisas en que se basan las conclusiones de la presente carta, son las siguientes:

1. De acuerdo con la Declaración sobre la Sintiencia Animal, que tuvo lugar en Cambridge el 7 de julio del año 2012, los animales deben ser reconocidos como sujetos de derecho ${ }^{1}$.

\footnotetext{
${ }^{1}$ Cambridge Declaration on Consciousness:

Disponible en URL: http://fcmconference.org/img/CambridgeDeclarationOnConsciousness.pdf
}

El 7 de julio de 2012 un prominente grupo internacional de neurocientíficos, neurofarmacólogos, neurofisiólogos y neuroanatomistas reunido para examinar los sustratos neurobiológicos de la experiencia consciente, firman este manifiesto en presencia del científico Steven Howkin en Cambridge, Reino Unido.

El texto de la Declaración dice: 
2.La Constitución Política de la República del Ecuador en su Art. 71 reconoce a la Naturaleza como sujeto de Derechos, por lo que, los animales como elementos constitutivos de la misma, merecen este tratamiento jurídico;

3.El Distrito Metropolitano de Quito, en total coherencia con la Carta Magna y las reformas que en este sentido se han venido dando en el mundo, promulga el 4 de Diciembre de 2017, la Ordenanza 188 en la que se reconoce a la Naturaleza y a los Animales como sujetos de derecho y los incluye entre los grupos de atención pioritaria del DMQ;

4.El Ecuador siendo parte de la Organización Mundial de Sanidad Animal (OIE), está comprometido con la observancia y aplicación de normas de bienestar animal.

En consecuencia, el régimen jurídico que les otorga dicha calidad, debe adecuarse a normas expresas de cuidado y protección.

A continuación las conclusiones de las 7 mesas de trabajo:

\section{MESA 1. COMUNICACIÓN Y PARTICIPACIÓN CIUDADANA: FAUNA URBANA}

1.La Comunicación entre Estado y ciudadanía para la construcción, aplicación y seguimiento de la política pública (local y nacional) respecto a los animales, constituye una necesidad urgente;

2.Esta comunicación solo será posible si se dejan de lado las diferencias y se enfatizan las coincidencias, mediante el reconocimiento por parte de las autoridades de representación ciudadana, de los aportes provenientes de la sociedad civil;

3.Se trabajará en la construcción de políticas públicas entre el Estado Central, Gobiernos Locales, Instituciones Gubernamentales Autónomas y Sociedad Civil;

4.Se procurará que las políticas públicas alcanzadas permanezcan en el tiempo, y obedezcan al principio de no retroactividad y progresividad en función de los cambios sociales que se vayan logrando;

5.Definir agendas desde el legislativo con la finalidad de construir política pública de protección animal;

6.El financiamiento para la aplicación de las políticas construidas, será tomado en cuenta dentro del presupuesto general del Estado.

\section{MESA 2. DESARROLLO ACADÉMICO DEL DERECHO ANIMAL}

1.Dar a conocer a la sociedad jurídica y no jurídica la existencia del Derecho Animal con el fin de generar pensamiento crítico;

2.Se conformará el Comité Especializado de Derecho Animal que conocerá de la cátedra, observará y sugerirá mejoras en sus contenidos a las Universidades; este Comité será conformado por profesionales especialista, encargados de asesoras a legisladores locales y nacionales en la creación y aplicación de las normas referentes al tema.

3.Proponer a las Facultades de Derecho, la inclusión del Derecho Animal en las

"La ausencia de un neocórtex no parece prevenir que un organismo experimente estados afectivos...el peso de la evidencia indica que los seres humanos no son los únicos que poseen los sustratos neurológicos necesarios para generar consciencia. Animales no humanos, incluyendo todos los mamíferos y pájaros y muchas otras criaturas, incluyendo los pulpos, también poseen estos sustratos neurológicos.” 
mallas curriculares. Inicialmente como materia opcional con pocos créditos; de esta manera los estudiantes en los primeros semestres podrán discernir y reconocer su existencia en los fundamentos de cada materia, desde una perspectiva transversal;

4.Posteriormente se propondrá la Cátedra de Derecho Animal, como materia en la carrera de Derecho, Veterinaria y Zootecnia, Agronomía y como Máster, tomando como referente los casos de Argentina y España;

5.Invitar a los abogados a crear dentro del Colegio y Foro de Abogados, una Comisión de Derecho Animal a fin de investigar su nacimiento, avance desde los cimientos mismos de la cultura y doctrina jurídica hasta el "animal turn" ${ }^{2}$ que hoy está reformando los regímenes jurídicos de los países;

6.Invitar a las Facultades de Derecho del país a conformar Institutos de Investigación de Derecho Animal, que además podrían defender casos puntuales en los Consultorios Jurídicos, con el apoyo de la Defensoría Pública;

7.Para la capacitación suficiente de los juristas se contará con el aporte de la fundación Victoria Animal y del ICALP, International Center for Animal Law and Policies con sede en Barcelona España.

\section{MESA 3. REFORMAS DE LEY Y APLICACIÓN}

1.Incluir el enfoque especializado en protección de derechos de los animales en la ley, los procedimientos y los actores relacionados.

2.La Defensoría Pública toma la decisión de incluir a los animales dentro del programa de VÍCTIMAS, para lo cual dos defensores públicos se especializarán en a materia. Para constancia de este acuerdo, se firmará un convenio entre la Defensoría Pública, la fundación Victoria Animal, Protección Animal Ecuador (PAE), LIBERA Ecuador y el ICALP, International Center for Animal Law and Policies (España) con la finalidad de capacitar a los profesionales que atenderán los casos de maltrato animal en los Consultorios Jurídicos Gratuitos coordinados por la Defensoría Pública. Todo esto inspirado en la Ordenanza Municipal 188 del DMQ que incluye a la Naturaleza y a los Animales dentro de los grupos de atención prioritaria;

3.Incluir al Grupo Parlamentario de Bienestar Animal en el impulso a los proyectos presentados de reformas al COIP, Código Civil y demás leyes conexas para conseguir un régimen jurídico conforme al reconocimiento de los animales como seres sintientes.

\section{MESA 4. ANIMALES DE GRANJA}

1.Incluir en el Reglamento de la Ley Orgánica de Sanidad Agropecuaria a cargo de AGROCALIDAD, los siguientes preceptos:

\section{DE LOS ANIMALES DESTINADOS AL CONSUMO HUMANO}

\footnotetext{
${ }^{2}$ Petters, A., Stucki, S., Boscardin, L. “ Animal Turn: Qué es y por qué ahora?

Nos referimos a un creciente interés académico en los animales, en las relaciones entre los humanos y otros animales, y en el papel y el estado de los animales en la sociedad (humana). El cambio de animal es un enfoque académico en animales en términos nuevos y bajo nuevas premisas. (pp.5)
} 
Art. 1.- El sacrificio de animales destinados al consumo humano se realizará únicamente en locales dirigidos y supervisados por médicos veterinarios zootecnistas capacitados en el tema quienes deberán garantizar que los métodos utilizados sean los autorizados para tales fines de conformidad con estándares internacionales de bienestar animal.

Se realizará mediante procedimientos, prácticas y protocolos que eviten el sufrimiento prolongado e innecesario durante el transporte, desembarque, ingreso al centro de faenamiento y sacrificio del animal.

En el caso de mamíferos y aves, el sacrificio estará precedido del aturdimiento efectivo del animal garantizando su plena inconciencia durante el proceso de desangrado. Los procedimientos deberán ser efectuados por operarios cuidadores de animales, mayores de edad, capacitados y autorizados.

Art. 2.- Los operarios encargados del sacrificio de los animales, deberán con cumplir los siguientes requisitos:

a. Ser mayor de edad;

b. Haber recibido capacitación en Bienestar Animal y aturdimiento efectivo (ICALP);

c. Someterse trimestralmente a exámenes psicológicos;

d. Estar autorizado por el Director de Rastro.

Art. 3.- Establecer mecanismos que impidan el sacrificio de hembras que se encuentren en el último $10 \%$ de estado de gestación.

Art. 4.- Queda prohibido el sacrificio casero de animales.

Art. 5.- Se propenderá a evitar el uso de publicidad engañosa para comercializar animales de consumo o sus derivados mediante la utilización de imágenes reales o gráficas que denoten conformidad de los mismos por ser consumidos.

ACCESO A INFORMACIÓN DE LOS PROCESOS DE BIENESTAR ANIMAL E IMPACTO AMBIENTAL DE LAS EMPRESAS QUE SE DEDICAN A LA PRODUCCIÓN DE ORIGEN ANIMAL

Art. 6.- Las empresas de rastro y centros de faenamiento publicas y privadas deberán contar con un circuito de control de todos sus procesos y esa información estar disponible de ser requerida a fin de garantizar el derecho del consumidor.

Art. 7.- De conformidad con la Ley Orgánica de Defensa del Consumidor, Capítulo IV, referido a la Información Básica Comercial, en el Art. 14 inclúyase el rotulado de los productos de origen animal de acuerdo a la siguiente clasificación:

Etiqueta 1: Garantía de cumplimiento de las 5 libertades básicas

a. Libres de hambre y sed

b. Libres de stress y ansiedad

c. Libres de disconfort térmico

d. Libres de dolor y enfermedad

e. Libres de expresar su comportamiento natural

Etiqueta 2: Cumple 3 de las 5 (especificar cuáles)

Etiqueta 3: Cumple 1 de las 5 (especificar cuáles)

Art. 8.- En la malla curricular educativa primaria, secundaria y superior se deberá incluir la ciencia del Bienestar Animal.

Art. 9.- Se implementará la trazabilidad ${ }^{3}$ de los animales y sus productos derivados

\footnotetext{
${ }^{3}$ REAL ACADEMIA DE LA LENGUA.- La trazabilidad, se basa en el registro de las huellas que deja un producto mientras transita por la cadena antes de llegar al consumidor final. Actualmente se trabaja para el desarrollo de un formato estándar que permita compartir y difundir la trazabilidad de manera sencilla.

La intención es desarrollar la facultad de repasar la trayectoria y el camino seguido por cada producto, algo que permitiría conocer de dónde vienen sus componentes, cuáles son los tratamientos que se le 
en toda la cadena de producción.

Art. 10.- Sustitúyase el término destrucción por eutanasia cuando se trate de animales que durante el exámen veterinario previo al sacrificio, hayan sido encontrados no aptos para su consumo.

\section{MESA 5. FAUNA SILVESTRE}

1.Los animales privados de su libertad que pueden ser reinsertados en su hábitat sean liberados;

2.Incluir a los peces para proteger sus derechos;

3.Alianzas público privadas para financiar los centros de manejo de fauna silvestre para aquellos animales que no pueden ser reincertados;

4.Fortalecer la educación y las sanciones;

5.Proponer la creación de actores judiciales especializados;

6.Que se incluya a fauna silvestre entre los animales susceptibles de defensa por parte de la Defensoría Pública;

7.Proponer acciones que protejan los hábitat naturales de las especies silvestres a través de programas de capacitación a los guardabosques y de voluntariado;

8.Que en todos los niveles se eduque en conservación y respeto a todos los animales; 9.Promover el etiquetado de bienestar animal, responsabilidad ecológica y comercio justo.

\section{MESA 6. ANIMALES EN ESPECTÁCULOS}

1.En una sociedad moderna y justa no se debería tolerar la violencia de ningún tipo por lo que se hace imprescindible ELIMINAR todo tipo de espectáculo público o evento privado en el que exista violencia o maltrato hacia cualquier tipo especie;

2.No se debe exeptuar de la protección jurídica a ninguna especie usada en espectáculos públicos o eventos privados considerando que todos los animales tienen derechos inherentes a su existencia, sensibilidad y sintiencia;

3.Se exhorta a la Asamblea Nacional y a la sociedad civil en general a que se impulse legislación más punitiva para casos de maltrato animal, acorde al derecho comparado;

4.Se invita a las Autoridades y Líderes de la Sociedad a crear mecanismos estructurales y permanentes que permitan disponer de financiamiento para proteger los derechos de los animales a través de EDUCACION y CONTROL del cumplimiento de la legislación vigente.

\section{MESA 7. ANTIESPECISMO Y POLITICAS SUGERIDAS DESDE LA SOCIEDAD CIVIL}

1.Mirar el problema desde todos los enfoques, incluyendo la sociología y la antropología desde el área rural;

2.Mantener un diálogo permanente con la institucionalidad del Estado;

3.Incluir en los programas de estudio de todos los niveles de educación contenidos relacionados con los derechos de los animales, desde la educación inicial hasta la

aplican y cómo se concreta la distribución. Esto posibilitaría, a su vez, mejorar la calidad del producto y aumentar el valor para el consumidor final. 
superior, a través de convenios entre las instituciones educativas y las fundaciones de protección animal.

4.Construir política pública que, entre otras, incluya educación en todos los niveles respecto a los derechos de los animales; desde la formación básica inicial hasta la profesional,

5.Generar alternativas económicas para los grupos que explotan animales aprovechando la agrobiodiversidad del país como la permacultura y el ecoturismo;

6. Observar la importancia de una revolución cultural, sino desde el reconocimiento de que no son máquinas de lucro.

7.Las plagas serán eutanizadas de formas técnicas que produzcan el menor dolor.

Seguros de que estos aportes incidirán en el trabajo que como Grupo Parlamentario por el Bienestar Animal se realice, suscribimos con optimismo.

Cordialmente,

Gabriela Alvear

COORDINADORA MESA 1

Verónica Aillón

COORDINADORA MESA 3

Shaddy Heredia

COORDINADORA MESA 5

Silvia Di Santo

COORDINADORA MESA 7
Lucía Salazar

COORDINADORA MESA 2

Lorena Bellolio

COORDINADORA MESA 4

Carlos Vásconez

COORDINADOR MESA 6 


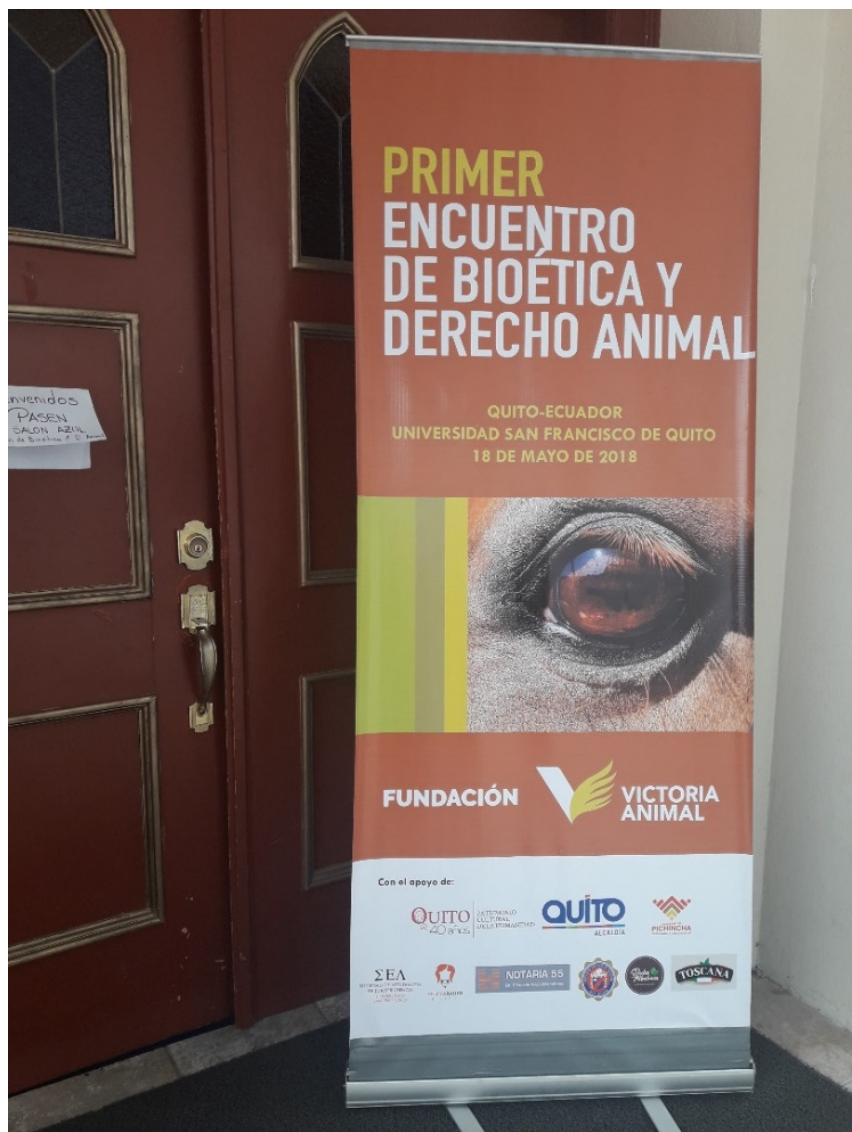

Ingreso al Primer Encuentro de Bioética y Derecho Animal realizado en Quito (Foto: cortesía de Verónica Aillón Albán)

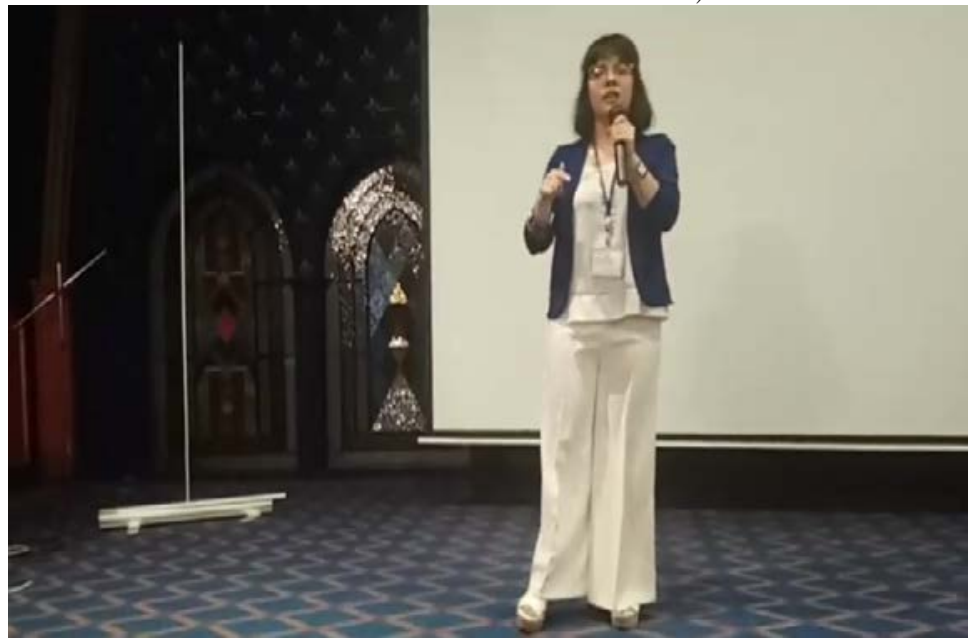

La Maestra de Ceremonias fue la Abg. Lucía Salazar (Foto: cortesía de Verónica Aillón Albán) 


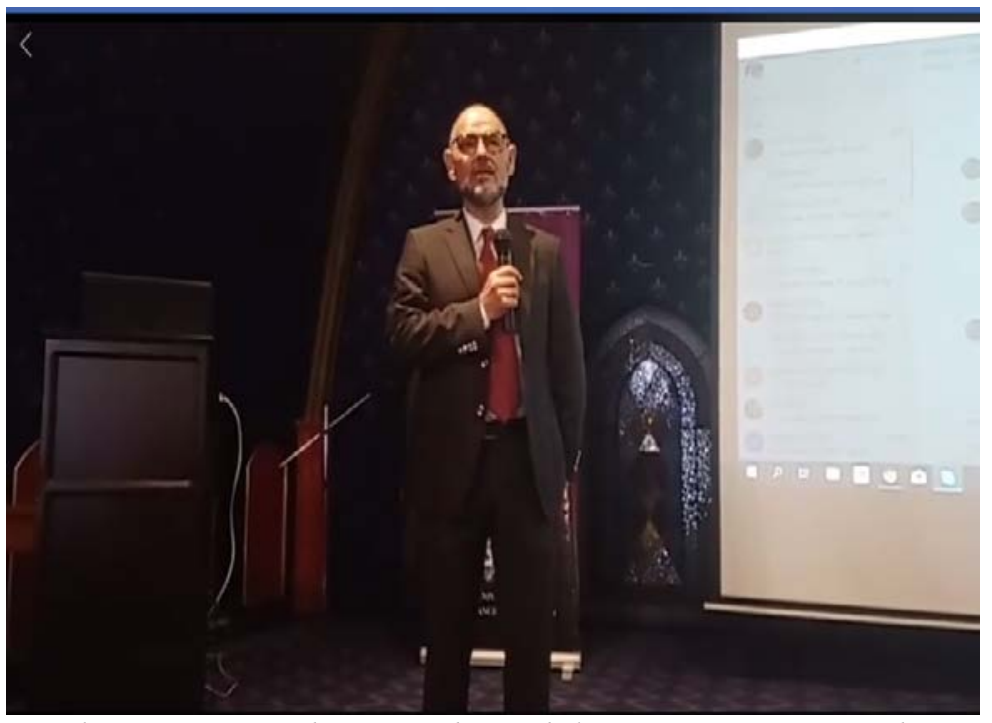

Dr. Farith Simon, Decano de Jurisprudencia de la USFQ (Foto: cortesía de Verónica Aillón Albán)

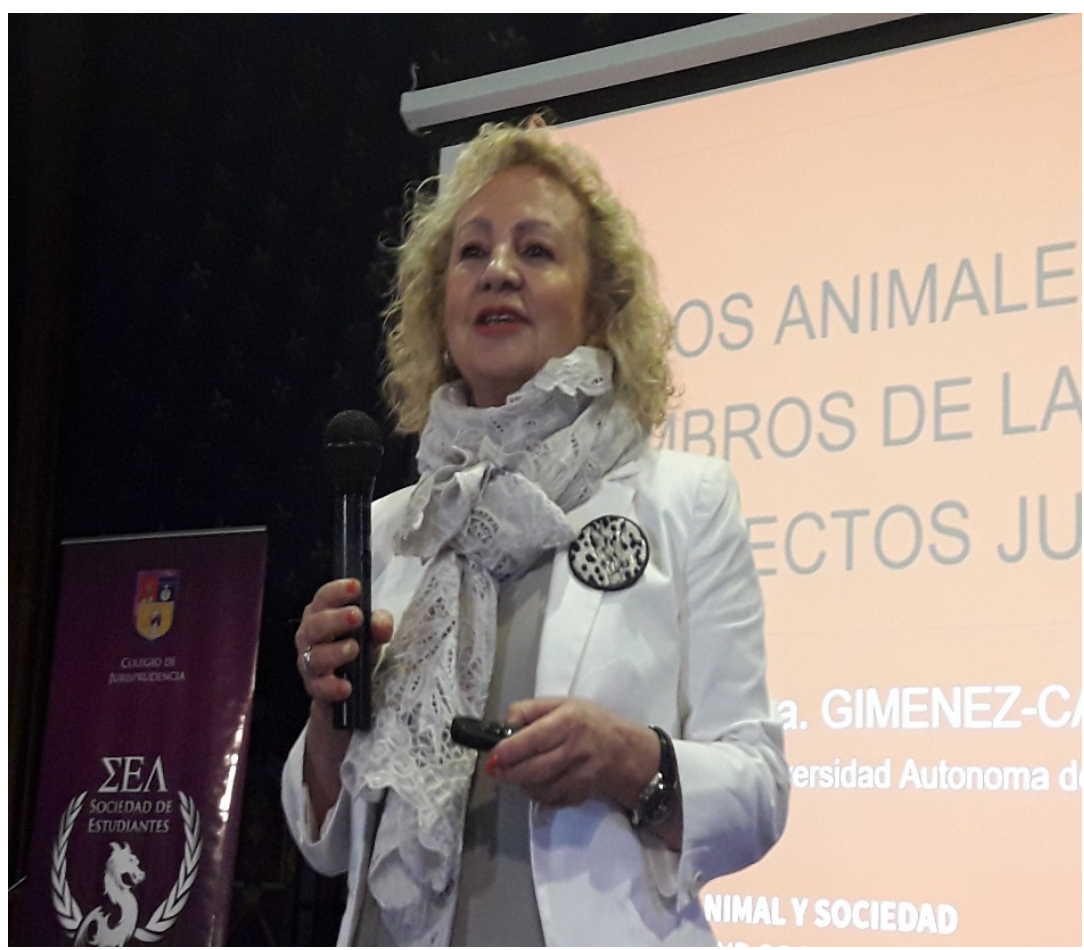

Ponencia Dra. Marita Giménez-Candela (Foto: cortesía de Verónica Aillón Albán) 


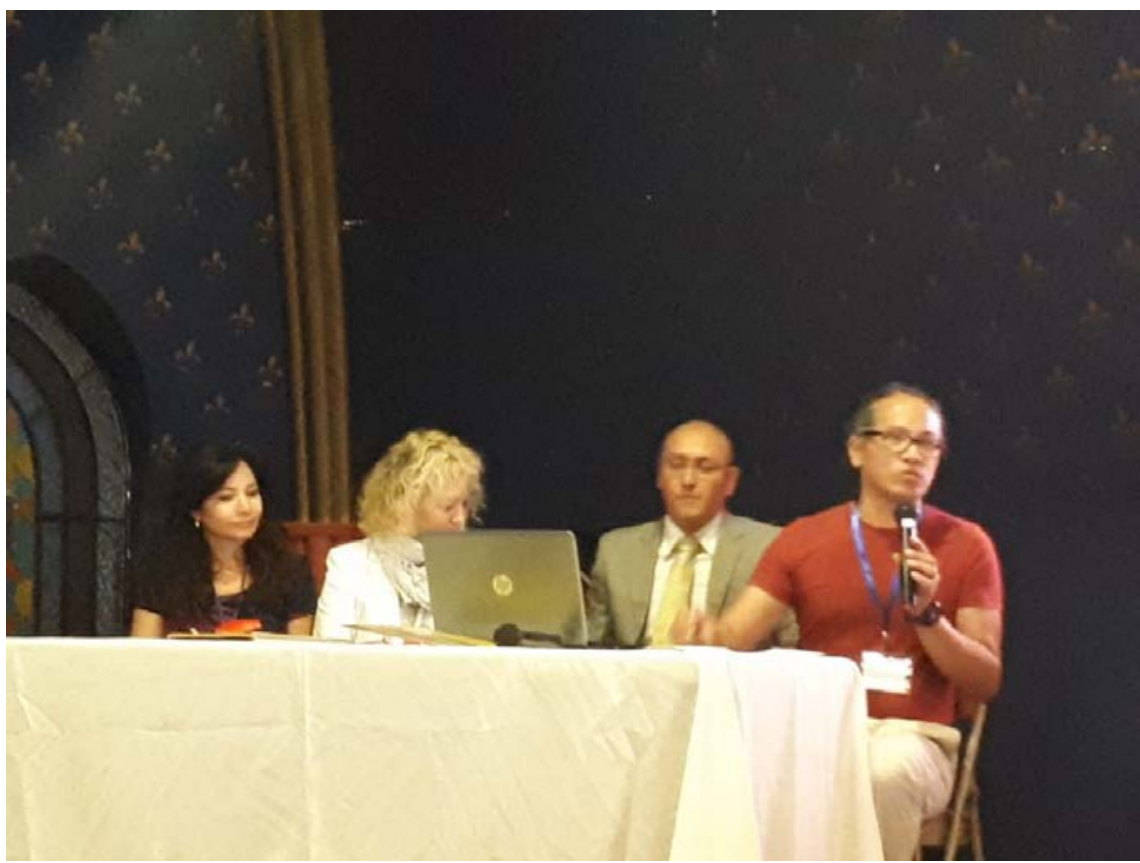

Dra. Verónica Aillón, Dra. Marita Gimenez, Dr. Hugo Echeverría y Dr. Luis Ávila (Foto: cortesía de María Gabriela Alvear)

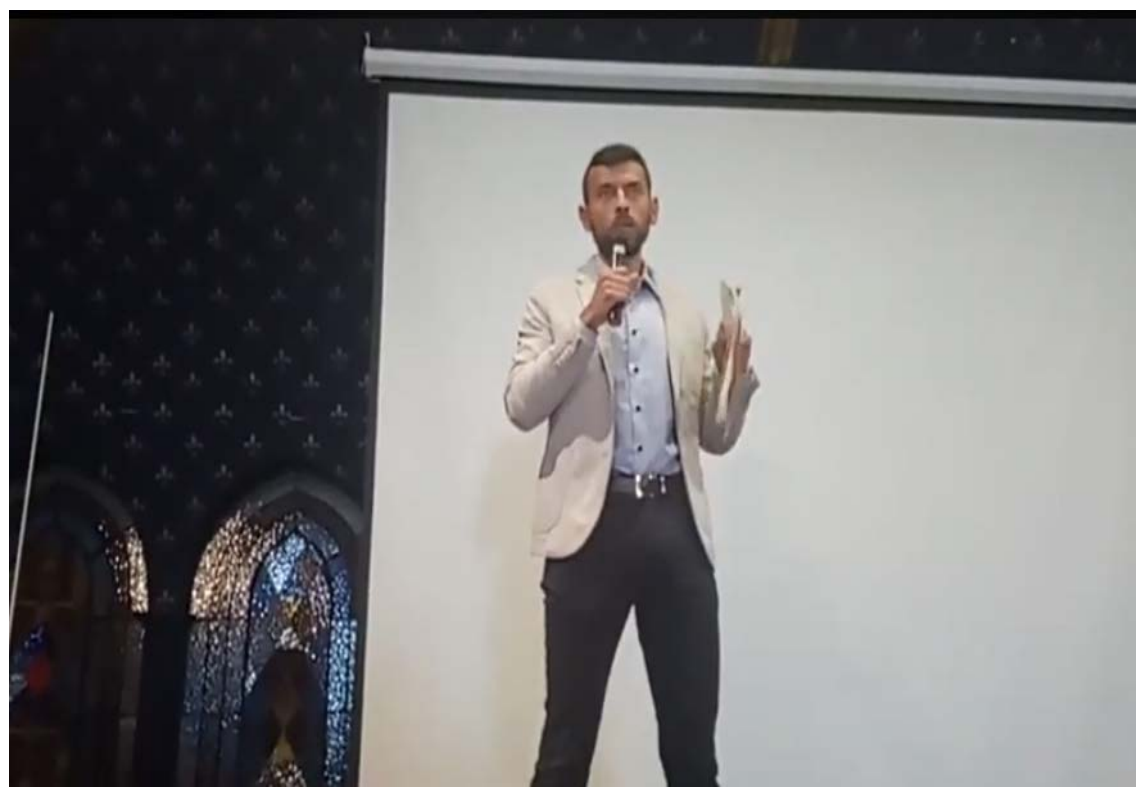

Ponencia Dr. Sebastián Palacios (Foto: cortesía de Verónica Aillón Albán) 


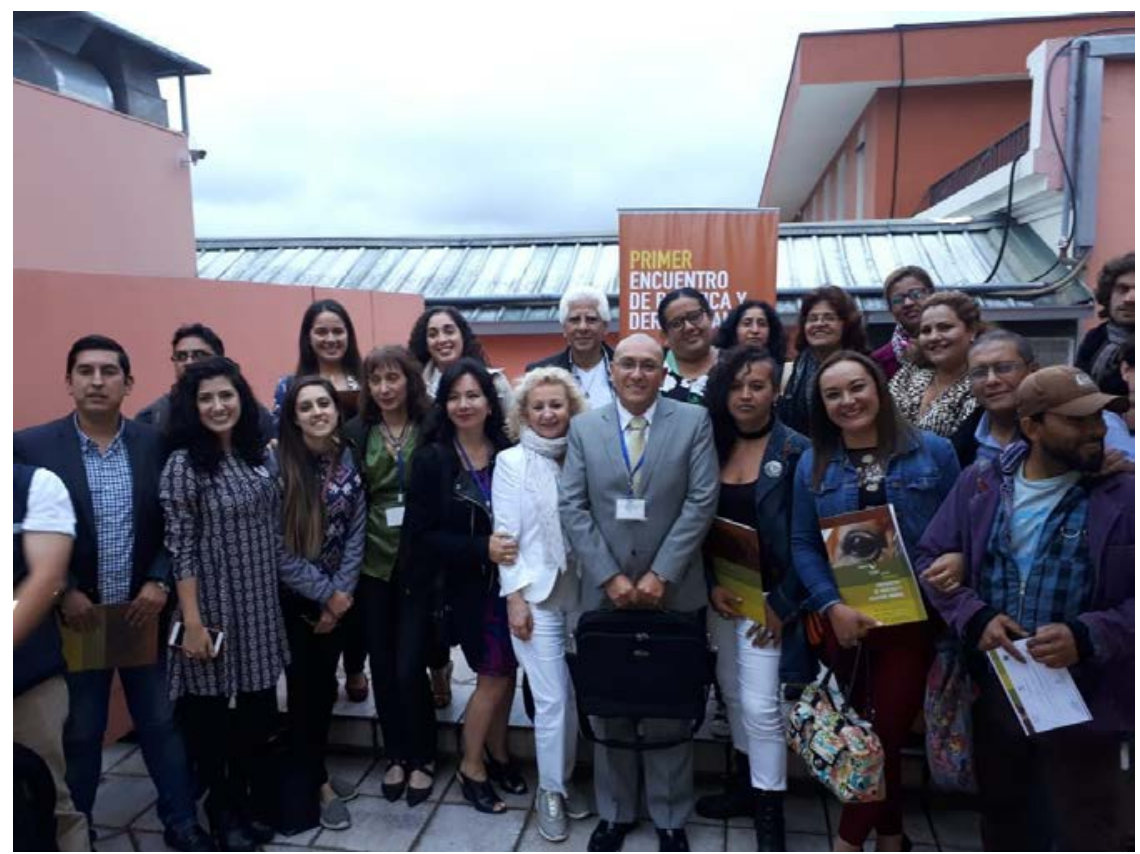

Algunos de los participantes en las mesas de trabajo (Foto: cortesía de María Gabriela Alvear)

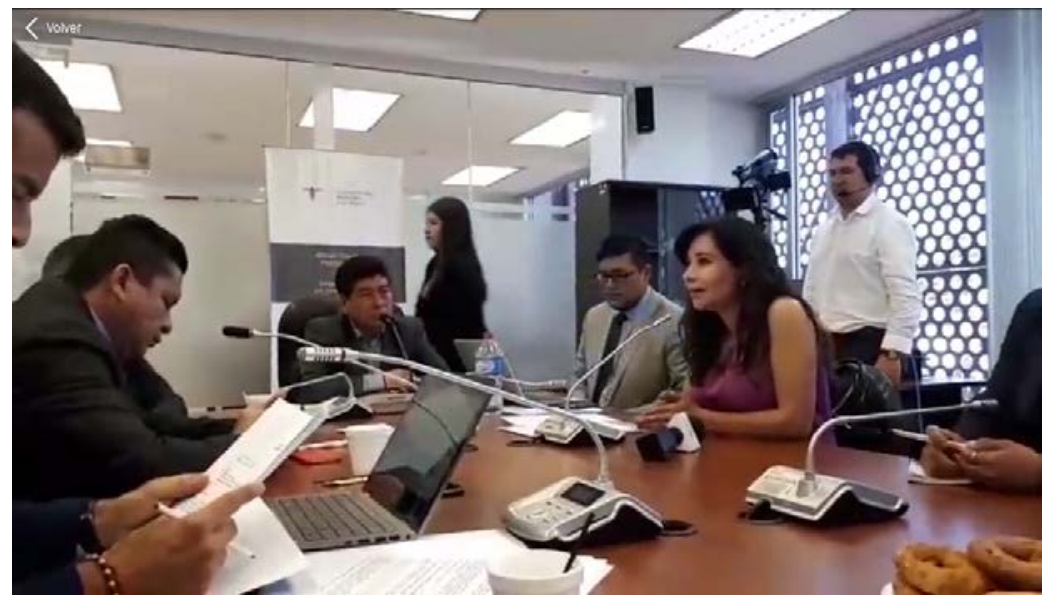

Entrega de la Declaración de Quito al Grupo Parlamentario por el Bienestar Animal 14 de junio de 2018 (Foto: cortesía de Verónica Aillón Albán) 